\title{
Study on the Spatial-Temporal Coupling Relationship between Economic Development and Industrial Water Use in West Liaohe River Basin
}

Pengda Lin, Zhijun Tong , Jiquan Zhang, Zhenhua Dong, Xiangqian Li

School of Environment, Northeast Normal University, Changchun 130117, China

Institute of Natural Disaster Research, Northeast Normal University, Changchun 130117, China

\section{西辽河流域经济发展与工业用水时空耦合关系 研究}

\author{
林鹏达，佟志军"，张继权，董振华，李向前 \\ 东北师范大学环境学院, 长春 130117 , 中国 \\ 东北师范大学自然灾害研究所, 长春 130117 , 中国
}

\begin{abstract}
Based on the center-of-gravity model and GIS, a measure of the spatial coupling of economic and industrial water use was obtained. Researching the trajectories, evolution and common characteristics the center-of-gravity of economic and industrial water use of 10 four $^{1}$ drainage from 2004 to 2013 in West Liaohe River basin, analyzes the temporal and spatial variation characteristics of industrial water use and economic development of each river basin, so as to find industrial water resources utilization status in the process of economic development, then explore the safety of industrial water, seek that reasonable utilization and protection of water resources in keeping the basin's economic development. Found: economy and industrial
\end{abstract}

作者简介: 林鹏达，(1992一)，女，汉族，东 北师范大学硕士, 主要从事生态安全风险分析 研究。

*通讯作者: 佟志军 (1977-), 男, 辽宁兴城 人, 副教授, 硕士生导师, 主要从事 $3 \mathrm{~S}$ 技术 及其在灾害风险评价与应急决策研究。 E-mail:gis@nenu.edu.cn water use have significant correlation from 2004 to 2013, their focuses move on the northeast and southeast direction, economic barycenter moving margins are small, but industrial water use gravity movement amplitudes are bigger. Space overlaps in six watersheds are strong, tending to gather, the moving directions of nine watersheds are inconsistent.

Key words: center-of-gravity model; GIS; West Liaohe River Basin; spatial-temporal coupling relationship; water resources utilization

\section{摘要}

采用重心模型和 GIS 技术, 衡量经济和工业用 水属性的空间耦合状况, 通过研究 2004-2013 年西辽河 10 个四级流域经济重心和工业用水 重心移动轨迹和演变规律及其共同变化特征, 分析了各流域工业用水与经济系统空间发展 的时空变化特征, 从而掌握流域经济发展过程 中工业用水资源利用状况, 进而探究工业用水 安全问题, 以寻求在保障流域经济发展的情况 下, 水资源得到合理的利用和保护。发现: 2004-2013 年流域经济与工业用水量间具有显 著相关关系, 二者重心一直在东北、东南方向 
Risk Analysis and Crisis Response in Big Data Era (RAC-16)

上移动, 经济重心移动幅度均较小, 而工业用 水重心移动幅度则差异较大; 其中 6 个流域二 者的空间重叠性较强、趋于聚集, 有 9 个流域 二者重心的移动方向出现不一致情况。

关键词: 重心模型; GIS; 西辽河流域; 时空 耦合关系; 水资源利用

\section{1. 引言}

21 世纪正是我国经济快速发展的重要时 期, 水资源作为不可或缺的基础性资源受到了 前所未有的重视。根据国际水资源管理学会研 究, 2025 年近 14 亿人将面临严重缺水。而近 年来, 我国经济的高速发展和城市化水平的不 断提高, 导致水资源需求和水污染负荷迅速增 加, 水的供需矛盾也更加尖锐。为推进中国可 持续发展战略的实现, 对自然资源利用以及环 境污染、能源消费与经济增长之间关系的研究 越来越受到学者们的关注 ${ }^{[1-4]}$ 。经济社会发展 与水资源利用之间紧密联系, 相互影响制约 [5-6]。本文中通过流域经济发展与工业用水重 心迁移的情况, 力图发现在经济发展驱动促使 工业用水量随之增长的情况下, 空间上工业用 水重心随着经济发展重心的迁移 (即水资源利
用的情况), 以得到两者迁移的耦合关系, 为 未来水资源的分配提供宏观参考; 同时, 工业 用水重心的迁移也代表着高要求高标准的新 工业建设。因此, 了解工业水资源利用与社会 经济增长的关系对工业水资源节约的影响具 有重大的意义。通过对西辽河各流域经济发展 与工业用水量的时空综合研究, 全面的了解各 流域工业用水利用状况, 为合理地保护、利用 水资源, 实现水资源与经济社会协调发展提供 决策依据。

\section{2. 研究区概况}

西辽河流域 $\left(116^{\circ} 50^{\prime}-124^{\circ} 06^{\prime} \mathrm{E}\right.$, $\left.41^{\circ} 03^{\prime}-45^{\circ} 13^{\prime} \mathrm{N}\right)$ 地处东北地区西南部, 内蒙古高原向东北松辽平原过渡的山地、丘陵 及冲积平原地带, 属于中温带半干旱季风气 候, 年均日照时数 $2800-3100 \mathrm{~h}$, 年均气温 $5.0^{\circ} \mathrm{C}-6.5^{\circ} \mathrm{C}$, 年均降水量 $350-400 \mathrm{~mm}$ 。本 文研究主要集中在内蒙古自治区范围内的西 辽河流域 (通辽市和赤峰市), 其行政区域包 括科尔区、开鲁县、科左中旗等 20 个旗、县、 区, 总面积 13.6 万 $\mathrm{km}^{2}$ 。（如图 1)

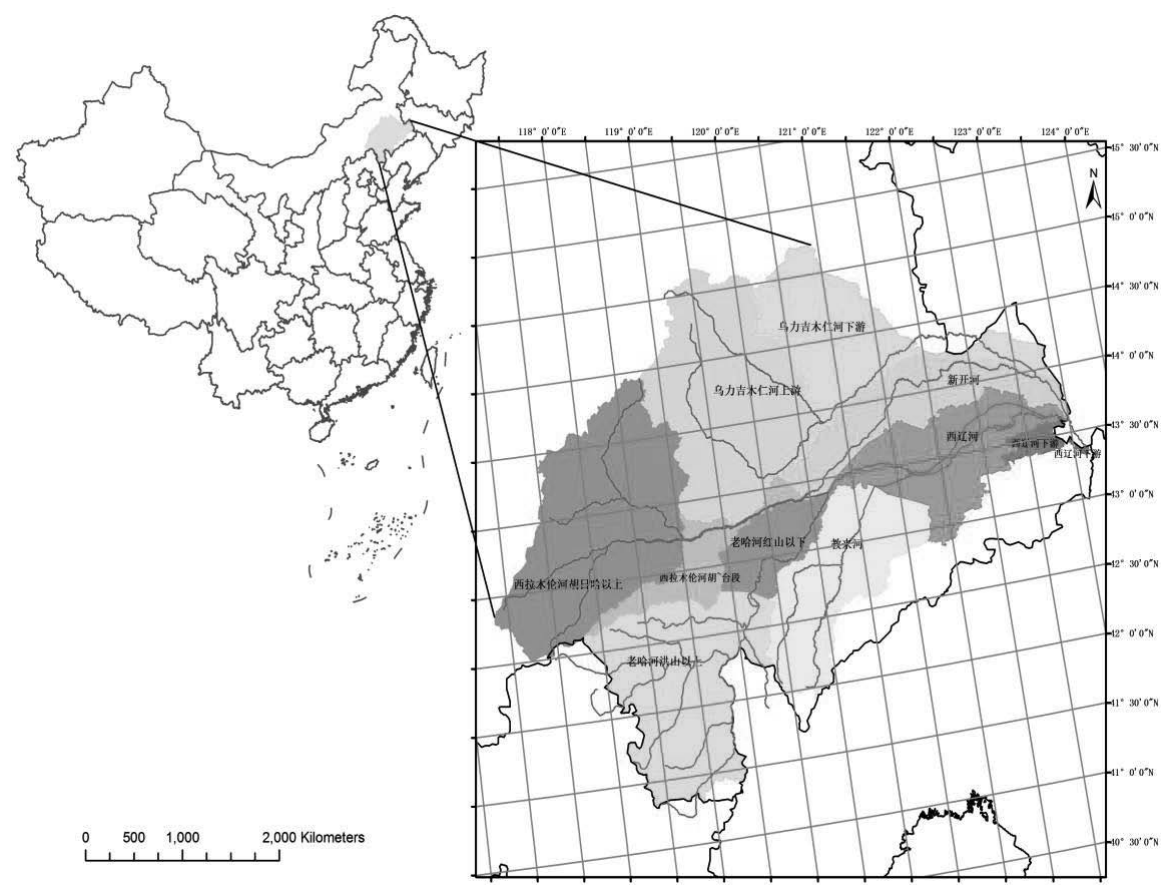

图 1 研究区图 
Risk Analysis and Crisis Response in Big Data Era (RAC-16)

\section{3. 数据与方法}

\section{1 数据来源}

数据的选取主要包括空间数据和属性数 据两部分。空间数据来自 1:400 万国家基础地 理数据库, 河流数据源自遥感影像解译。属性 数据主要来源于通辽市统计局、水利局《通辽 市统计年鉴》、赤峰市统计局、水利局《赤峰 市统计年鉴》及《内蒙古水资源公报》，其中 地区生产总值作为各旗县经济的测度代表; 各 年份的地区工业生产总值与万元工业增加值 用水量的乘积作为各旗县工业用水量的测度 水平代表。在 GIS 软件支持下, 根据采集到的 基本统计单元界线以及流域界线, 将各行政区 的地区生产总值与工业用水量按面积权重分 配到 10 个四级流域中, 分别构建流域经济和 工业用水数据库。

\section{2 重心分析模型 ${ }^{[7]}$}

重心 (加权平均中心) 应用于社会、经济 和环境问题研究中, 是指在区域空间上存在某 一点, 在该点各个方向上的力量对比能够维持 均衡。重心的位置与考察的区域的形状和相关 的活动在该区域的布局状况有关。区域重心同 经济总量一样, 可作为宏观经济指标, 用来衡 量国家或区域发展方向、空间均衡以及评估政 策效果等 ${ }^{[8]}$ 。

在研究中, 假设一个区域由 $\mathrm{n}$ 个次一级区 域构成, 那么该区域某种属性的 “重心”:

$$
\bar{x}=\sum_{i=1}^{n} M_{i} X_{i} / \sum_{i=1}^{n} M_{i}, \quad \bar{y}=\sum_{i=1}^{n} M_{i} Y_{i} / \sum_{i=1}^{n} M_{i}
$$

其中: $\left(X_{i}, Y_{i}\right)$ 示第 $i$ 个次一级区域中心的 经度值和纬度值, $M_{i}$ 表示第 $i$ 个次一级区域 的某种属性的量值。本文选取各流域的几何重 心作为次一级区域中心。

$$
\theta_{s-k}=\frac{n \pi}{2}+\operatorname{deg}\left\{\arctan \left[\left(Y_{s}-Y_{k}\right) /\left(X_{s}-X_{k}\right)\right]\right\}
$$

其中 $\theta_{S-K}$ 表示相对于 $k$ 时期的 $s$ 时期重 心移动的角度变化, $X 、 Y$ 表示重心的地理 经纬度; 界定正东方向角度为 $0^{\circ}$, 所有旋转 角度取欧氏几何角度单位, 逆时针旋转为正
向。

$$
D_{s-k}=C * \sqrt{\left(X_{s}-X_{k}\right)^{2}+\left(Y_{s}-Y_{k}\right)^{2}}
$$

其中 $D_{s-k}$ 表示相对于 $k$ 时期的 $s$ 时期重 心移动的距离, $C$ 为将地理经纬度坐标单位 $\left({ }^{\circ}\right)$ 转化为平面距离 (KM) 的常数系数, 一 般取其值为 111.111 ; 其他参数同上。

\section{3 重心耦合性分析模型}

经济重心 $\left(x_{g}, y_{g}\right)$ 和工业用水重心 $\left(x_{i}, y_{i}\right)$ 的空间重叠性用两者间的距离表 示, 距离越近则重叠性越高, 从静态的角度考 察两个重心空间耦合的态势。计算公式如下：

$$
S=\sqrt{\left(x_{g}-x_{i}\right)^{2}+\left(y_{g}-y_{i}\right)^{2}}
$$

对于其变动轨迹的一致性, 以二者重心相 对上一时间点产生位移的矢量交角 $\theta$ 来体现， 其值在 $0^{\circ}-180^{\circ}$ 间范围内, 因此可用它的 余弦值作为变动一致性指数 $(C)$ :

$$
C=\cos \theta=\frac{\Delta x_{g} \Delta x_{i}+\Delta y_{g} \Delta y_{i}}{\sqrt{\left(\Delta x_{g}^{2}+\Delta y_{g}^{2}\right)\left(\Delta x_{i}^{2}+\Delta y_{i}^{2}\right)}}
$$

\section{4. 结果与分析}

\section{1 流域经济与工业用水量属性变化特征}

2004-2013 年, 西辽河各流域生产总值整 体呈现持续上升状态, 西辽河流域生产总值由 546. 96 亿元上升至 3144.27 亿元, 增长了近 6 倍; 工业总用水量由 1.29 亿 $\mathrm{m}^{3}$ 上升至 4.48 亿 $\mathrm{m}^{3}$, 增长了近 4 倍, 经历了加速上升到减速 上升的变化过程。由表 1 可知，2004-2013 年, 各流域经济与工业用水间均表现出强相关 性。可见经济因素是驱动工业用水的重要因 素, 工业发展带来了经济增长也随之带来了工 业用水量的增加, 经济与工业用水量的关系密 切。基于经济与工业用水量间的显著相关关 系, 进一步分析其时空上的演变特征。

\section{2 流域经济与工业用水时空演变}

\section{2.1 经济与工业用水重心迁移特征}

根据上述测算方法, 由图 2 发现 2004-2013 年期间, 乌力吉木仁河上游工业用 水重心从巴林左旗向阿鲁科尔沁旗移动, 西拉 
Risk Analysis and Crisis Response in Big Data Era (RAC-16)

表 1 2004-2013 年流域经济与工业用水量相关性分析

\begin{tabular}{lcc}
\hline \multirow{2}{*}{ 地区 } & \multicolumn{2}{c}{ 2004-2013 年 GDP 与工业用水量 } \\
\cline { 2 - 3 } 教来河 & Pearson 相关性 & 相关性 \\
老哈河洪山以下 & 0.968 & $<0.05$ \\
老哈河洪山以上 & 0.942 & $<0.05$ \\
乌力吉木仁河上游 & 0.875 & $<0.05$ \\
乌力吉木仁河下游 & 0.942 & $<0.05$ \\
西拉木伦河胡日哈以上 & 0.969 & $<0.05$ \\
西拉木伦河胡日哈 ${ }^{厶}$ 台段 & 0.917 & $<0.05$ \\
西辽河 & 0.937 & $<0.05$ \\
西辽河下游 & 0.897 & $<0.05$ \\
新开河 & 0.979 & $<0.05$ \\
\hline 而成 & 0.962 & $<0.05$ \\
\hline
\end{tabular}

木伦河胡日哈以上工业用水与经济重心在林 西县与克什克腾旗间移动。而其他 8 个流域, 二者重心均保持在同一个行政单元内移动。并 且西辽河各流域经济与工业用水重心均保持 向东的移动, 经济重心移动幅度较小, 而工业 用水重心移动幅度差异较显著。具体地, 在经 济重心的变动中, 只有西辽河下游、乌力吉木 仁河下游分别保持着向东北和东南方向连续 的移动, 重心移动幅度前者较后者小, 此期间 这两个流域的经济发展趋势较平稳; 而工业重 心的变动中, 保持迁移方向一致的流域有西拉

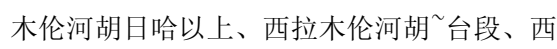
辽河下游, 乌力吉木仁河下游, 前三者移动方 向为东北向, 重心移动幅度依次变小, 后者向 东南方向移动, 移动幅度由大变小, 并逐渐趋 于平稳。其他流域的经济重心与工业用水重心 则在东北与东南方向上往返移动, 移动幅度相 对较小, 这个过程中经济发展与工业用水消耗 不稳定, 一直处于寻求均衡的区域发展格局状 态。出现以上重心迁移现象可能是由于西辽河 流域覆盖面积广阔, 其地理位置上与东北三省 同属一个范畴, 在经济上联系密切, 在资源上 互补强, 其经济社会的发展与东北地区老工业 基地的振兴有着紧密关联。且近些年, 通辽市 抓住西部大开发和振兴东北老工业基地的历 史发展机遇, 提出了 “一主两翼” 经济发展模 式, 以主轴为能源工业, 两个侧翼为农畜产品 加工业和重化工工业, 对全市经济结构进行战 略性调整。同时西辽河平原交通地理条件优 越, 与东北三省大城市邻近, 接受着它们的辐 射带动作用。

\subsection{2 经济与工业用水时空耦合分析}

空间位置和属性值是决定重心的主要因 素, 经济重心和工业用水重心的分离与靠近是 区域发展过程中的表现。将 2004-2013 年经济 与工业用水重心的迁移方向及距离代入重心 耦合性分析模型得到两者的空间重叠性与变 动一致性 (图 3 和图 4), 再结合图 2 定量、 动态、直观地对流域经济与工业用水重心的时 空耦合态势进行分析, 得到图 3 和图 4。

(1)西辽河各流域二者重心的空间重叠性 由大到小分别是: 西辽河下游、西拉木伦河胡 台段、老哈河洪山以下、老哈河洪山以上、 教来河、西辽河、乌力吉木仁河上游、新开河、 西拉木伦河胡日哈以上、乌力吉木仁河下游。 前 6 个流域空间重叠性较强, 除了教来河在 2011-2013 年间空间重叠性降低, 其他流域均 保持在较低变化幅度范围, 二者的重心趋于聚 集, 工业用水紧跟经济发展的趋势在进行移 动; 后 4 个流域空间重叠性则整体较差。

(2)西辽河各流域经济重心与工业用水重 心的变动一致性多数年份大于 0 , 二者都保持 向东运动。具体表现有两类: 第一, 10 个流 域中只有西拉木伦河胡 ${ }^{\sim}$ 台段二者重心的迁移 在翁牛特旗保持着相同方向, 即经济的发展带 动了工业产业及用水的转移; 第二, 其他 9 个 流域二者重心的迁移均出现过移动方向不一 致的情况, 尤其是西辽河下游流域曾出现两次 二者重心迁移方向完全相反的情况。工业水资 源节约是节水工作中的重点领域。经济发展越 高速的区域, 对于用水要求越高, 工业用水重 心跟不上, 可能工业用水大户仍主要集中在旧 
Risk Analysis and Crisis Response in Big Data Era (RAC-16)
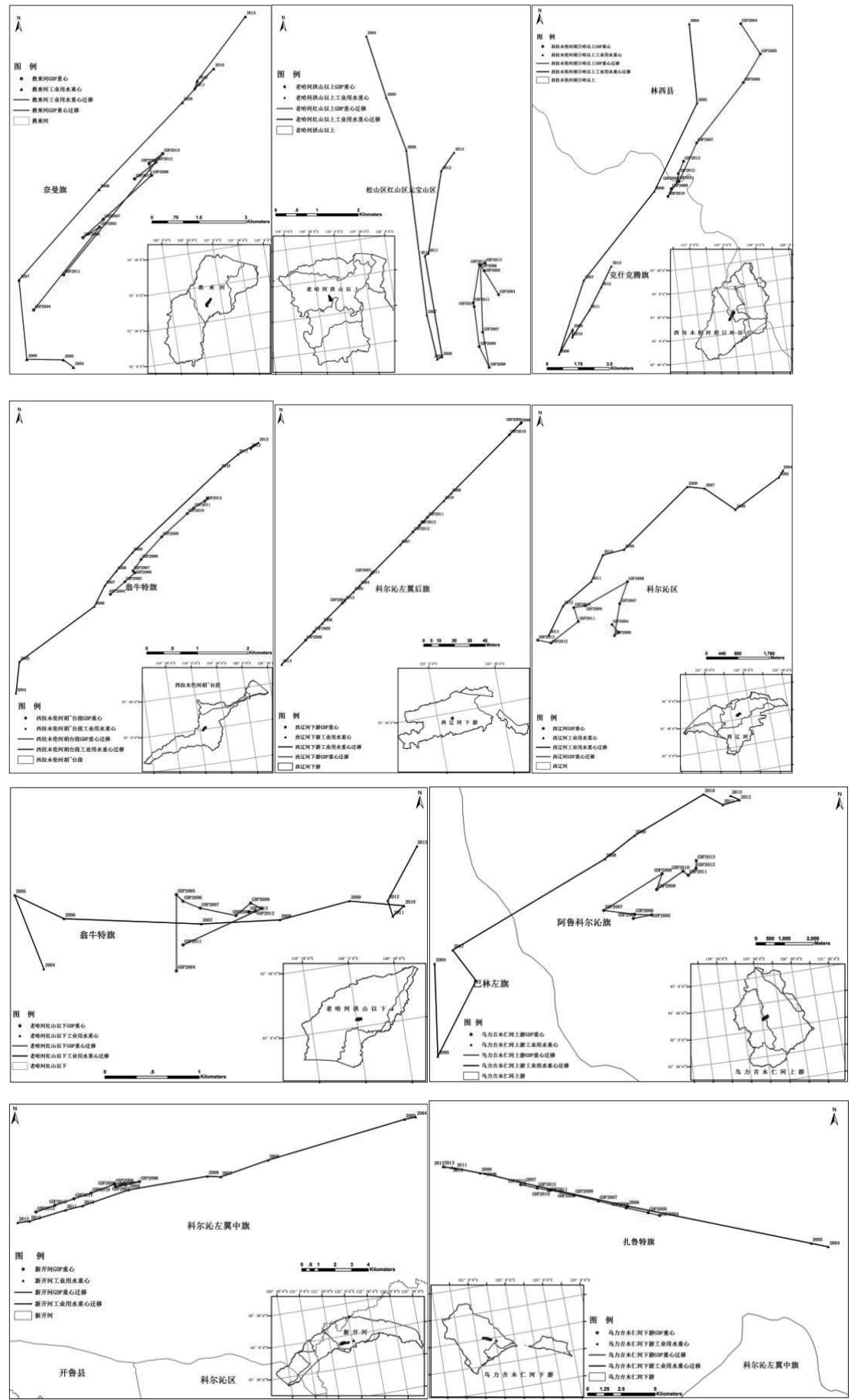

图 2 2004-2013 年流域经济与工业用水重心迁移变化图 
Risk Analysis and Crisis Response in Big Data Era (RAC-16)

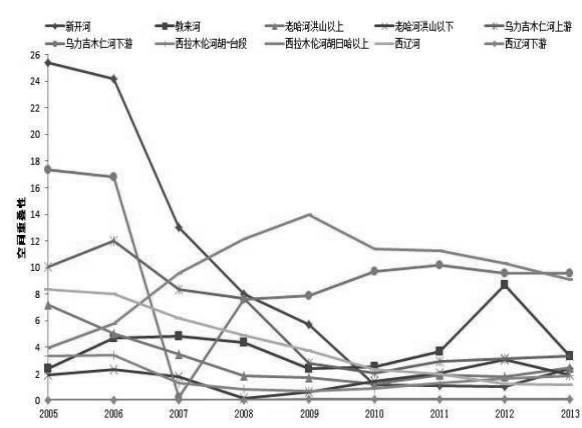

图 3 空间重叠性

工业区且该区工业用水比重不降反增。这样不 仅会减速经济发展, 而且也会严重影响新工业 区的发展和水资源供给, 出现新旧工业区的水 争夺, 出现用水安全问题。

\section{5. 结论}

西辽河流域在不同的地理环境和资源约 束等条件下, 具有独特的经济发展格局, 其发 展与东北地区老工业基地的振兴有着密切的 联系。本文通过分析流域经济与工业用水重心 的迁移, 掌握区域经济发展过程中水资源利用 状况, 发现重心时空耦合态势表现为工业用水 重心落后于经济的迁移, 水资源的供应方向比 较稳定, 水资源供应量在缓慢增长。因此在保 证经济可持续的发展过程中, 需进一步带动新 型节水工业的建设、节水工艺的实施, 提高工 业用水效率，也同时抑制和降低工业用水中的 水资源过度消耗。而要从根本上解决干旱缺 水、用水安全问题, 必须跨流域调水, 利用文 得根水利枢纽加快实施绰尔河引水工程, 从嫩 江调水到西辽河, 以满足西辽河流域能源基地 及工业、城镇用水需求, 缓解西辽河断流及经 济社会发展急需用水 ${ }^{[9]}$ 。且经济与工业用水重 心明显的东移, 对处于半干旱地区的西辽河流 域经济社会发展、生态环境建设和新型城镇化 格局也具有重要的影响。

\section{Acknowledgements}

The study is financially supported by the National Non-Profit Research Program of China (No.201401015).

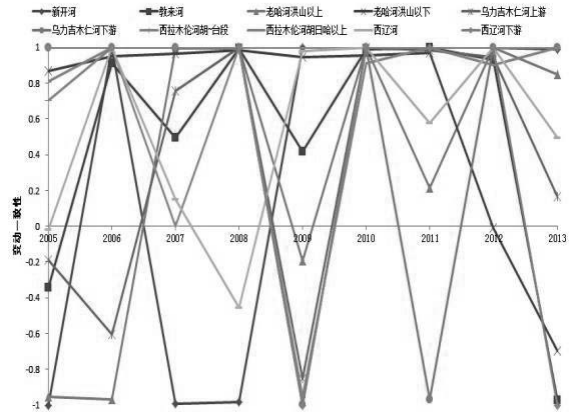

图 4 变动一致性

\section{致谢}

本文以水利部公益性行业科研专项经费 项目（201401015）为项目支撑。

\section{参考文献}

[1]C. Y. Song, R. Zhang, A.X. Zhou, M. Hong . Water Security Risk Assessment of the Yellow River Basin Based on Constrained-Random Weight and Cloud Model. Journal of Risk Analysis and Crisis Response, 2013, 3(4):201-209.

[2]张兵兵, 沈满洪. 工业用水与工业经济增长, 产业结构变化的关系. 中国人口资源与环 境, 2015, 25(2) : 9-14.

[3] 岳立, 白婧, 郭山宁. 基于超效率的中国工 业用水效率分析. 石家庄经济学院学 报, 2013, 36(6):51-55.

[4] 赵海霞, 蒋晓威. 长江三角洲经济与工业污 染重心演变及脱钩机理. 中国环境科 学, 2013, 33 (10) : 1911-1919.

[5]姜蓓蕾, 耿雷华, 市锦宇, 等. 中国工业用水 效率水平驱动因素分析及区划研究. 资源 科学, 2014, 36(11).

[6] 贾绍风, 张士锋, 夏军. 工业用水与经济发 展的关系: 用水库兹涅茨曲线 $[\mathrm{J}]$. 自然资 源报. 2004, 19 (3) : 279-284.

[7]张兴榆, 黄贤金, 赵雲泰, 等. 近 10 年江苏 省土地利用重心与经济重心迁移轨迹对 比分析. 长江流域资源与环境, 2011, 20 (1) : 14-20.

[8]赵小风, 黄贤金, 张兴榆, 等. 区域经济重心 与 $\mathrm{COD} 、 \mathrm{SO}_{2} 、 \mathrm{TSP}$ 排放重心演变路径分析 - - 以江苏省为例. 长江流域资源与环 境, 2010 (3) : 225-230.

[9]梁团豪,谢新民,崔新颖,等. 西辽河流域水 资源合理配置研究 [J]. 中国水利水电科 学研究院学报,2009,7(4):291-295. 